\title{
El estatuto científico de la antropología
}

\section{Sumario:}

1.1. Ciencias naturales y ciencias humanas: historia de una polémica inacabada.

1.2. La antropologia y las ciencias humanas: demarcación y relaciones.

1.3. Estatuto epistemológico de la antropologia.

1.4. Superación del humanismo y del etnocentrismo:

\subsection{CIENCIAS NATURALES Y CIENCIAS HUMANAS: HISTORIA DE UNA POLEMICA INACABADA}

El concepto mismo de ciencias humanas se forjó en la secular polémica que las comparó y opuso insistentemente con las ciencias naturales. En el transcurso de la misma se utilizaron como sinónimos de ciencias humanas conceptos como ciencias morales, ciencias del espíritu, ciencias noológicas; ciencias de la cultura, ciencias normativas, etc. También se utilizaron como sinónimos los conceptos de ciencias del hombre, los de ciencias sociales y ciencias históricas. Algunos de ellos son claramente inadecuados (ciencias morales, normativas, sociales, históricas) por ser demasiado restrictivos; pero no entramos por el momento en ello. Para nuestro propósito nos basta una noción descriptiva de las ciencias humanas como aquellas disciplinas que se ocupan de estudiar las diferentes actividades de los hombres en tanto que agrupados en colectividades definidas, de sus relaciones entre sí y con las cosas, de sus productos e instituciones. En este sentido, como es obvio, se contraponen a las ciencias naturales en cuanto que éstas se ocupan de investigar los fenómenos exteriores al hombre, del cosmos o de la naturaleza. No es 
preciso distinguir para nuestro propósito entre ciencias exactas y ciencias naturales.

Podemos distinguir en las confrontación entre las ciencias naturales y las ciencias humanas los siguientes periodos y singularida$\operatorname{des}^{1}$.

\section{a) Periodo de las clasificaciones}

El problema de una posible autonomía de las ciencias humanas, el planteamiento de una metodología específica de las mismas en relación con las ciencias naturales es, en realidad, bastante reciente. Se inició en el s. XVII, se afirmó progresivamente en el s. XVIII y se impuso solamente en los ss. XIX y XX. Hasta entonces se mantenia sin discusión la clasificación aristotélica de las ciencias en tres clases: ciencias teóricas (análisis de las causas necesarias), ciencias poéticas (producción del agente) y ciencias prácticas (la actividad del agente). Nos ocuparía demasiado espacio analizar la compleja red de factores que modificaron esta situación. Baste aducir únicamente dos: uno, de naturaleza teórica: la distinción cartesiana entre "res cogitans" (espíritu, alma) y "res extensa" (materia, cuerpo); otro de naturaleza práctica: el gran desarrollo de las ciencias naturales a partir de la metodologia y de los trabajos de Galileo, que contrastaba con el estancamiento de la temática abordada hasta entonces con el método filosófico. Desde entonces se ha tendido a considerar el modelo de las ciencias naturales como modelo de toda cientificidad. Esta actitud se impuso en el s. XVIII; en el XVII se buscó la solución más bien en una nueva clasificación de las ciencias.

Los intentos de clasificación de las ciencias se sucedieron desde el s. XVII hasta el XIX. A falta de suficientes elementos de juicio y en ausencia de una teoría general, la clasificación se ofrecia como una solución. Una de las primeras y de mayor influjo fue la de Bacon (De dignitate et augmentis scientiarum, 1623). El criterio clasificador lo sitúa en las diferentes facultades del espíritu humano, que completa con la distinción entre la naturaleza y el hombre. Tenemos asi la imaginación fuente de la poesía; la memoria, fuente de la historia, y la razón, fuente de la filosofía. Esta, a su vez, se subdivide en teología (ciencia de Dios), ciencias de la naturaleza

1. J. FREUND, Las teorias de las ciencias humanas. Barcelona, 1975. Advierto, de una vez por todas, que debo mucho a esta obra para la elaboración de este primer apartado. 
(que pueden ser especulativas y prácticas) y ciencias del hombre. Estas ciencias humanas son de dos tipos: las del hombre individual (en las que distingue dos subtipos: ciencias del cuerpo y ciencias del alma) y las del hombre que vive en sociedad, que son tres: ciencia de la conversación, de los negocios o economía y la del gobierno o política.

Es de notar cómo Bacon no se limitó a clasificar las ciencias entonces existentes, sino que anticipó y dio nombre a varias todavía por crear. Por lo demás, la clasificación baconiana actuó como paradigma de la época; la presentada por el propio D'Alembert en su Discurso preliminar de la Enciclopedia no hace más que reasumirla y cambiar su nomenclatura. Mucho mayor interés tiene la de Ampere (Essai sur la philosophie des sciences, 1834), dos siglos más tarde. Se trata también de un proyecto muy ambicioso, que encubre una teoría general de las ciencias. De la misma nos interesa particularmente su división entre las ciencias cosmológicas o ciencias de la naturaleza y ciencias noológicas o ciencias del espíritu, división que se hará clásica en la cultura alemana. Las ciencias cosmológicas se dividen, a su vez, en cuatro ramas (ciencias matemáticas, físicas, naturales y médicas), cada una de las cuales se subdivide varias veces. Las ciencias noológicas dan lugar también a cuatro ramas: ciencias filosóficas, dialegmáticas (arte y lenguaje), etnológicas y politicas. A destacar las ciencias etnológicas, entre las que distingue la etnología, la arqueología, la historia y la hierología (sagrado).

\section{b) Siglo XVIII}

Todo el siglo estuvo dominado epistemológicamente por las ciencias naturales. Las ciencias humanas se harian científicas en la medida en que adoptaran los métodos de aquellas. Los trabajos de Newton reforzaron esta posición. Pero se trataba de una epistemología ingenua: se pensaba que bastaba con naturalizar los fenómenos humanos para poder explicarlos. Tal fue la postura de Helvetius, La Mettrie y Holbach. Proliferaron los estudios sobre religión natural, moral natural, política natural, etc. El resultado fue una nueva metafísica, de corte materialista y mecanicista, que será rechazada de modo unánime poco después. Sin embargo, contemporánea de la naturalista; aunque sin apenas eco por entonces, existió otra corriente que, apoyándose en el dualismo cartesiano, mantuvo la irreductibilidad ontológica y metodológica entre espíritu y materia, pensamiento y naturaleza, que se hará vigorosa en el s. XIX. 


\section{c) La conciencia histórica}

El s. XIX se abre con un nuevo planteamiento del problema: no se trata ya de defender una diferencia entre los diversos tipos de ciencia, sino de proclamar la autonomía de las ciencias humanas. El problema epistemológico se hizo obsesivo. No sólo se propugnó la especificidad de los métodos de las ciencias humanas, sino que se pensó en dotarlas de una nueva lógica a partir de la herencia kantiana, que luego evolucionó hacia un franco idealismo. La fuerza catalizadora de este movimiento en pro de las ciencias humanas fue, sin duda, la toma de conciencia de la historicidad de lo humano. La Ilustración y vico lo habian anunciado cada cual a su modo (los ilustrados, con la idea de progreso; Vico, con su "scienza nuova"). Pero ahora es Alemania donde prende masivamente el historicismo en torno al concepto de "Volksgeist" ("espíritu del pueblo"). La historia parece arrojar nueva luz sobre la política, el estado, la sociedad, el derecho, el arte, etc. Los debates y las controversias se mantienen y se replantean sin cesar. Cada cual esgrime la "verdadera" economía, política, etc., es decir, el objeto de las ciencias humanas.

En la escuela histórica de los juristas (Savigny) el historicismo no sólo es fuente de verdad, sino que es también una violenta reacción contra el materialismo mecanicista precedente y contra el racionalismo de la Ilustración. Lo mismo puede decirse de la escuela histórica de los economistas. Sólo la "Nueva Escuela Histórica" (Schmoller) abandonó el concepto metafísico de la historia para centrarse en estudios concretos como el artesano en la Edad Media, la economía doméstica antigua, etc. Nace con ella igualmente el sentido de la relatividad de las teorías. El método histórico es sólo una guía para la investigación positiva. Se afirma, pues, que las ciencias humanas son al mismo tiempo ciencias empíricas, cuyos resultados son válidos sólo cuando son verificables. La sintesis hegeliana y el materialismo histórico de Marx que se desarrollaron en este marco serán estudiados más adelante.

\section{d) El positivismo}

Al mismo tiempo que el historicismo en Alemania, el positivismo dominaba en Inglaterra y Francia, dando lugar a los primeros trabajos epistemológicos sobre la unidad y especificidad de las ciencias humanas. Probablemente fue Saint-Simon el primero en concebir las ciencias humanas como ciencias positivas. No obstante, serían Comte y Mill quienes realizaron el proyecto. 
Comte privilegia el estatuto de las ciencias humanas hasta el punto de que, gracias a la constitución de la sociología, la ciencia se convierte al mismo tiempo en filosofía positiva en cuanto sistema general del saber humano. Por tanto la sociología ocupa simultáneamente tres ámbitos: ciencia particular en cuanto física social (sociología actual); ciencia general que se ocupa del objeto de las actuales ciencias humanas; y ciencia filosófica, englobadora de las ciencias y de las instituciones y ciencia suprema.

Mill (Stuart), en cambio, definió desde el punto de vista lógico el estatuto diferencial de las ciencias humanas. Pero, al mismo tiempo, Mill abogó por la unidad de la ciencia en base a la unidad metodológica del razonamiento científico. El "razonamiento primario" es la inducción, de la cual proceden dos razonamientos derivados: la experimentación y la deducción. De ahí los dos tipos de ciencias: experimentales (que establecen nuevas inducciones) $\mathrm{y}$ deductivas (que infieren nuevas propuestas a partir de inducciones ya establecidas). Por tanto, entre ambas se dan diferencias de grado, no de naturaleza. Por lo demás, las ciencias humanas son todavía muy imperfectas, pero progresarán con el tiempo hasta hacerse exactas, puesto que las acciones humanas obedecen también a leyes. Hasta cierto punto, pues, Mill satisfizo su aspiración explícita de ser el $\mathrm{Ba}$ con de las ciencias humanas, aunque fue mucho más continuador de éste en las naturales. No obstante, ambos tipos de ciencias siguen el mismo modelo epistemológico: a) establecimiento de leyes causales hipotéticas sobre las leyes empiricas que gobiernan los fenómenos; b) de las leyes causales se deduce el efecto previsto; c) se verifica seguidamente la diferencia entre la previsión teórica de la deducción y el resultado efectivo.

Wundt, en cambio, parte del supuesto de que las ciencias humanas existen y, por tanto, no es preciso constituirlas. Eso sí, of recen particularidades que es preciso respetar, pero los objetos de las ciencias del espíritu son siempre, al mismo tiempo, objetos de las ciencias de la naturaleza. Claro es que Wundt pensaba exclusivamente en la psicologia, compendio de las ciencias humanas. Las ciencias de la naturaleza captan lo real mediante la experimentación directa; la psicología, en cambio, lo capta en una experiencia vivida; esto es, en relación con un sujeto que siente. Wundt distingue, no obstante, dos ramas en la psicologia: la individual (el individuo genérico y su estructura psiquica), basada en el método experimental; y la psicología colectiva (relaciones grupales, Iengua, arte, mitos, costumbres), basada en el método comparativo. Pero experimentación y comparación son dos aspectos metodológicos de 
la inducción y ambas clases de psicologia se complementan. Incluso ambas pueden fundirse en una panpsicologia o teoría sistemática de las ciencias del espíritu, con dos vertientes: ciencias históricas (estudia las formas temporales y evanescentes de la creatividad humana como filología, mitología, historia) y ciencias sociales (estudia las formas duraderas e institucionalizadas como sociología, derecho, economía, etc.).

\section{e) W. Dilthey (1833-1911)}

Puede ser considerado el teórico de las ciencias humanas. La prosecución de una epistemología autónoma de las mismas no sólo fue el objetivo principal de su obra, sino que lo introdujo en el centro de la reflexión de modo permanente. Se situó en la confluencia de las dos tendencias: en el historicismo, pero con la crítica de la razón histórica; y en el positivismo, pero sin otorgar a la sociología ni a la psicología un estatuto englobante (aunque privilegia a la psicología).

Dilthey acepta de Mill que las ciencias humanas son ciencias positivas, pero no su subordinación metodológica a las ciencias de la naturaleza. En efecto, Dilthey plantea un dualismo epistemológico para respetar la particularidad propia de las Ciencias del Espíritu y de las Ciencias de la Naturaleza. Y, en especial, por la necesidad de romper con el naturalismo. Porque las ciencias del espíritu se basan en otro tipo de inteligibilidad, pero son autónomas como las de la naturaleza (Introducción al estudio de las ciencias del espíritu, 1883). No admite ninguna comparación metodológica en relación con las ciencias naturales: las ciencias del espiritu tienen una originalidad propia y se han desarrollado de modo diferente. Es más, también la propia razón se forma en la historia. Representan dos modos de acceder a la realidad: por la experiencia externa y por la experiencia interna; ambos modos son igualmente legitimos; Dilthey es el primero en llamar la atención sobre los límites del conocimiento propio de las ciencias naturales dentro de su misma esfera. Lo propio de las ciencias del espíritu es la inteligibilidad histórica, la captación de lo singular e individual en la obra humana. Explicamos la naturaleza y comprendemos la vida psíquica.

La metodologia más adecuada para las ciencias del espíritu es la biografía, ya que permite una combinación de historia y psicología, por una parte, y por otra combina la generalización y la individualización. En último término, lo fundamental es que las ciencias del espíritu nos permiten "comprender", mientras que las cien- 
cias de la naturaleza no pasan de "explicar". A diferencia de la observación y experimentación, que permanecen exteriores y extrañas al objeto, la comprensión intenta coincidir estructuralmente con 10 psíquico-histórico. Al final, Dilthey recogerá también la tradición hermenéutica, que le posibilita una reconstrucción creadora. La hermenéutica es el descubrimiento de significados, pero conservando su singularidad. La hermenéutica le permitirá incluso moderar su contraposición de explicación-comprensión: la interpretación descubre que entre ambos métodos sólo hay una diferencia gradual. Dilthey recoge asimismo la distinción de Wundt entre ciencias históricas y ciencias sociales, liberándolas del panpsicología.

\section{f) La herencia del historicismo}

La postura de Dilthey fue secundada ampliamente, sobre todo en Alemania, pero también en Francia (Bergson). Una premisa común fue el rechazo del naturalismo en todas sus formas. Igualmente se acentuó la distinción entre naturaleza e historia.

La posición naturalista fue, en realidad, bastante diversificada: a) naturalismo materialista, generalmente ateo (La Mettrie, Holckel): b) naturalismo metodológico: las ciencias de la naturaleza representan el modelo científico único; es la postura de $\mathrm{H}$. Taine, filósofo a su pesar; c) naturalismo moderado, en dos vertientes: los que parten de un principio, teoría o concepto de las ciencias de la naturaleza y los que se limitan a aplicar el método experimental a las ciencias humanas, sin previa justificación. Lo común a todas las formas de naturalismo es su tendencia a regentar las ciencias humanas $y$, en el fondo, a sustituirlas, tanto para explicar como para dirigir las actividades humanas, como ha señalado Gusdorf ${ }^{2}$.

En el historicismo es preciso distinguir igualmente dos formas: a) historicismo absoluto, de corte filosófico, que propugna una oposición radical entre naturaleza e historia; b) historicismo metodológico, creado por los neokantianos de Baden, renuncia a ser una cosmovisión, para limitarse a ver en la historia unas condiciones de inteligibilidad de lo real. En oposición al naturalismo que niega la especificidad de las ciencias humanas, los historicistas enfatizan los límites del conocimiento tanto en las ciencias de la naturaleza como en las ciencias humanas; destacan igualmente la colaboración de ambas ciencias, pues una misma realidad puede ser objeto de una investigación naturalista y de una investigación histórica. Pe-

2. G. GUSDORF, Introduction aux sciences humaines (Paris 1960) 363-364. 
ro han destacado, sobre todo, la autonomia de las ciencias humanas, que deben estudiarse conforme a su estatuto lógico propio. En definitiva, el saber científico sigue dos rutas: una naturalista; in pos de leyes universales; otra histórica, en pos de lo singular.

Windelband distingue en esta línea unas "ciencias nomotéticas" y unas "ciencias ideográficas". Tal distinción se basa en la diferencia entre juzgar y apreciar. Juzgar se limita a la realidad de un hecho; apreciar añade la valoración del mismo. Este criterio se completa con el de la base o no base experimental. Existen unas ciencias racionales, que no parten de la experiencia (matemáticas, filosofia); y unas ciencias de la experiencia, que se subdividen en dos niveles: ciencias nomotéticas (nomos=ley), orientadas a descubrir leyes generales en la naturaleza y en la evolución, y ciencias ideográficas (idion=singular), orientadas a estudiar el objeto en su singularidad en la historia, la cultura, etc. Windelband no acepta la denominación de "ciencias del espíritu", por parecerle equivoco (una ciencia del espíritu puede ser nomotética, como la psicologia). Pero ciencias nomotéticas e ideográficas no se oponen en virtud de su objeto, sino de su diferente modo de abordar el análisis de los fenómenos dados en la experiencia. De ahí que deban colaborar en la investigación, aunque para ello sea preciso reformar la lógica, que sólo se ocupa de lo genérico y no de lo singular.

Rickert (1863-1936) prosigió la obra de Windelband con atención preferente a definir los limites del conocimiento en las ciencias de la naturaleza y a consolidar la autonomía de las ciencias humanas. Rickert distingue dos actitudes epistenológicamente divergentes: a) la del conocimiento generalizante, centrado en lo que es común a varios objetos; b) la del conocimiento individualizante, atenta a lo singular. Ambas actitudes fundan, respectivamente, las ciencias de la naturaleza y las "ciencias de la cultura"; las primeras son nomotéticas, las segundas, ideográficas. No existe divergencia de objeto de estudio, sino de método. La base de las ciencias de la cultura no es la psicología sino la historia. Ahora bien, la divergencia de metodologías se relaciona con una selección de valores: la conceptualización naturalista es mecánica, esto es, carente : de teología y de significación; la conceptualización culturalista, en cambio, es teleológica y significativa. Un fenómeno cultural resulta incomprensible sin referirlo a los valores que le confieren un sentido. Por la demás, Rickert no acepta la distinción entre explicación y comprensión, que le parecen procedimientos complementarios y que, por 10 mismo, deben ser utilizados en ambos tipos de ciencias. 
La única diferencia real entre ambas radica en su diferente actitud metodológica.

\section{g) El paradigma "comprensión".}

Como hemos visto, las diversas tendencias del historicismo convienen en afirmar que las ciencias naturales y las humanas difieren únicamente en lo que respecta al método, pero que ambas poseen en común tanto el objeto como la validez científica. Sin embargo, la distinción popularizada por Dilthey entre "explicación" (erklären) y "comprensión" (verstehen) fue tomada por algunos filósofos existencialistas (Jaspers, Bollnow, Marcel) y sociólogos (Weber, Simmel) como el principal criterio epistemológico para establecer una diferenciación lógica y sistemática entre ambos tipos de ciencias, aunque cada uno con diversas matizaciones. También Bergson debe ser incluido en el grupo por su rígida distinción entre "entendimiento" e "intuición".

Jaspers fue quien con mayor radicalidad mantuvo la irreductibilidad entre explicación y comprensión (Psicopatología general 1913). La explicación tiene por objetivo determinar las causas de los fenómenos, a partir de la inducción, hasta establecer relaciones constantes o leyes generales. Se centra en la investigación causal y en la verificación de sus resultados; pero las relaciones establecidas permanecen exteriores a los objetos mismos. La comprensión, en cambio, tiene por objetivo la captación de las relaciones internas y profundas mediante la empatía (Einfühlung); a diferencia de la explicación, no parcela la realidad, sino que respeta su totalidad original. Posee, además, un sistema de verificación propio: la evidencia.

La irreductibilidad entre ambas es, en primer lugar, epistemológica. En efecto, explicación y comprensión se sitúan a niveles diferentes de inteligibilidad de la realidad; aunque esta diferencia no excluye las relaciones mutuas. Pero en su Filosofía (1932) la irreductibilidad alcanza también a los objetos respectivos: la realidad está constituida por esferas especificadas entre las que 'se encuentran la esfera de la naturaleza y la esfera del espíritu. Es más, también la finalidad entre ambos procedimientos es irreductible: La explicación se centra sobre la validez objetiva y la utilidad técnica; la comprensión, por el contrario, se orienta hacia los valores. La crisis de las ciencias humanas radica, según Jaspers, en su proclividad a imitar a las ciencias naturales.

Bergson mantuvo independientemente de la tradición alemana 
una postura similar en base a su distinción entre "entendimiento" e "intuición". El primero se sirve para acceder a lo real de conceptos esquemáticos, siempre uniformes e inmóviles, parcela la realidad vital, de la que abstrae aspectos parciales de un modo artificial y hasta arbitrario. Hasta cierto punto, el entendimiento mete a presión la realidad en sus esquemas, dando lugar asi al mundo de las cosas medibles y controlables desde el exterior. La intuición, en cambio, comienza por sintonizar con el flujo incesante de la realidad en permanente evolución, evoluciona ella misma con la realidad, reelabora incesantemente sus conceptos nacidos en la experiencia vivida y de la conciencia de la duración (Matiére et moire, 1896).

Max Weber (Economia y sociedad, 1924). Existe muy generalizado el prejuicio de que Weber opuso radicalmente el concepto de comprensión al de explicación. No obstante, la realidad es que Weber defendió muy convincentemente la realidad del método comprensivo en sociología y en las ciencias humanas - vinculado a su teoría de los tipos ideales - pero la utilización del mismo nunca es unilateral, sino asociado al método explicativo. Se trata de una "explicación comprensiva". La "interpretación causal válida" se completa mediante la "captación interpretativa del sentido o connexión del sentido". Asi, en palabras de Weber "explicar significa algo asi como captación de la conexión del sentido en que se incluye una acción". O, más claramente todavía: "una interpretación causal correcta de una acción concreta significa: que el desarrollo externo y el motivo han sido conocidos de un modo certero y el mismo tiempo comprendidos con sentido en su conexión $/ . . /$ si falta la adecuación del sentido nos encontramos meramente ante una probabilidad estadística no susceptible de comprensión" ${ }^{3}$. En definitiva, la comprensión completa el proceso explicativo causal al aportar algo esencial en la actividad humana, los motivos o finalidades - conscientes o no- de los sujetos, lo que permite atribuirle significación. Comprender significa dar una explicación completa de un hecho humano. La explicación de un asesinato, por ejemplo, no es completa mientras no conozcamos los móviles y el sentido del acto. Las ciencias naturales, en cambio, se satisfacen con una explicación por causas, alcanzando un grado mayor o menor de probabilidad estadística. De todos modos, la distinción entre ambos tipos de ciencias no se desprende del concepto mismo de la ciencia. Weber no acepta el criterio de cantidad-cualidad como discriminatorio, pues ambos

3. M. WEBER, Economía y sociedad I (México 1969) 8-11. 
tipos de ciencias deben utilizar aspectos cuantitativos y cualitativos; ni siquiera la tendencia generalmente-particularizante. En realidad, lo que Weber propugna es la subordinación del método al objeto y al investigador: éste puede apelar al procedimiento metudológico que las condiciones del objeto aconsejan para llegar a resultados válidos y fiables.

Tampoco es cierto que Weber atribuya mayor grado de certeza al método comprensivo que al explicativo. En primer lugar, porque ambos están asociados; pero es que, además, Weber afirma expresamente que una explicación causal completa - difícil de obteneres garantía de cientificidad. Ahora bien, la investigación causal es sólo un medio por el cual la ciencia se orienta hacia la inteligibilidad de lo real; esto es particularmente cierto en las ciencias humanas en las que la relación causal exige ser completada por la relación significativa.

Bollnow, profesor de Tubinga, es autor de una notable monografía sobre la metodología de las ciencias humanas (Die Methode der Geisteswiserschaften, 1950). Su planteamiento inicial es el de examinar los fundamentos reales del mayor prestigio científico de que gozan generalmente las c. de la naturaleza. Su conclusión es que estas ciencias, ni presentan la unidad que se les atribuye, ni ofrecen el rigor científico característico. Por otra parte, Bollnow suscribe enteramente la postura de Weber: ni la comprensión se limita a las ciencias del espíritu ni la explicación a las naturales, sino que ambos métodos cooperan en el proceso investigador. Es más la explicación aparece como un auxiliar quf viene a complementar cuando se hace preciso, pero siempre al servicio de la comprensión.

Obviamente, el problema mayor que se presenta por la línea de la compresión es el de la objetividad de las investigaciones. El criterio de cientificidad es el de la validez universal de los resultados obtenidos, independientemente de su relación con el investigador y de las circunstancias singulares. Esta exigencia difícilmente puede satisfacerla el metodo comprensivo, con to que las ciencias humanas parecen condenadas de antemano a ser acientíficas. Sin embargo Bollnow cuestiona el criterio de validez universal: ¿pertenece realmente a la esencia de la ciencia o, más bien, fue impuesto indebidamente por las ciencias físicas? ¿quién ha deciđido que el criterio de validez universal, propio de las ciencias naturales se convierta en el criterio de la cientificidad?

Bollnow advierte, finalmente, que el abandono del criterio de validez universal no significa el abandono de la objetividad; este es 
uno de los prejuicios derivados del anterior, porque nada impide que se mantenga la objetividad sin validez universal, pues ambos conceptos no están lógicamente implicados; menos todavia tras la revolución antropológica. En todo caso afirma Bollnow; siguiendo Ia filosofía existencialista no tiene sentido en ciencias humanas preguntarse por una verdad fuera de una situación concreta, pues la privaria de su base existencial indispensable.

\section{h) La crisis de la ciencia}

A partir de la inspiración fenomenológica, por un lado, y de los presupuestos del humanismo hegeliano-marxista-freudiano, por otro, la polémica sobre el estatuto de las ciencias humanas se ha planteado también cuestionando las bases mismas del criterio de cientificidad, al mismo tiempo que se intenta replantear las ciencias humanas de nuevo cuño.

El propio Husserl había orientado su fenomenología como una ruptura de las bases epistemológicas del naturalismo, del psicologismo y del historicismo simultáneamente, aunque sólo en Ideen II, publicado póstumamente, se encuentra un desarrollo sistemático. Husserl no sólo rechaza la imposición del criterio científico de la física como un método universal, sino que cuestiona la noción misma de objetividad. En principio, porque ningún método puede considerarse definitivo; menos todavía presentarse como modelo universal. El objetivo de las ciencias humanas es realizar investigaciones válidas, no someterse al método naturalista. Naturalismo, psicologismo o historicismo representan tendencias unilaterales y exclusivistas. La auténtica base de las ciencias naturales está en la fenomenología. Como la esfera natural se rige por la causalidad, la del espíritu está dominada por la intencionalidad y los valores. Por eso los procedimientos causales en las ciencias humanas resultan insuficientes. Pero, finalmente, Husserl recae en el absolutismo: sólo la intuición de las esencias (Wesenschau) permite construir una ciencia universal, al igual que una ciencia eidética de las ciencias humanas.

Cassirer y Rothaker, en cambio, han buscado la especificidad propia de las ciencias humanas en la misma historia del desarrollo de estas disciplinas al igual que Gusdorf en su ambicioso proyecto titulado Las ciencias humanas y el pensamiento occidental. Esta historia muestra una oposición permanente : entre la explicación causal y la explicación formal. El auge de las ciencias positivas experimentales impuso el paradigma de la positivación. Pero las cien- 
cias naturales han reconocido posteriormente los límites de la explicación causal.

Según Cassirer, no sólo han tenido que reconocer tales limites, sino que han debido incluir los aspectos formales, tanto en biología como en física. El principio de la forma resulta imprescindible en las ciencias naturales, pero es el constitutivo de las ciencias humanas. Es preciso tener en cuenta que el concepto de forma en Cassirer se apoya tanto en la tradición neokantiana como es la Psicologia de la Gestalt. Los aspectos configurativos, estructurales, descubren una nueva dimensión de lo real. De ahí su vigencia en las ciencias naturales. Pero son centrales en las ciencias humanas, aunque éstas tampoco excluyan el principio de causalidad (Sobre la lógica de las ciencias del espiritu, 1942).

La "Teoría crítica de la sociedad" o Escuela de Franckfurt parte de supuestos hegelianos-marxistas-freudianos para presentar una crítica todavía más radical de la "razón científica" desde una perspectiva tanto lógica como sociológica. Horkheimer y Adorno llegan hasta los fundamentos racionalistas sobre los que se sustenta la epistemología de la ciencia para trazar luego las grandes líneas de una teoría: social del conocimiento. En efecto, por una parte, el método científico no hace más que reflejar la estructura racional - represiva- de la sociedad occidental (de ahí que la razón cientifica cumpla una destacada función conservadora del orden existente. La rigurosa estructuración de la lógica formal es su mejor exponente); por otra, el racionalismo analítico ignora absolutamente no sólo los aspectos inconscientes e irracionales, sino también las mediaciones histórica y social de las acciones. De ahí su propuesta de una racionalidad dialéctica, que sustituya a la racionalidad analítica imperante (Dialéctica de la Ilustración, 1942-44).

El positivismo sociológico, por ejemplo, estudia los hechos sociales como inmediatos e incondicionados; precisamente su verdad está en su inmediatez. Pero ignora que los hechos sociales (y humanos en general) están "mediados" tanto histórica como socialmente. $\mathrm{Y}$ esta mediación es la que configura realmente su verdad. El método positivo resulta, pues, radicalmente insuficiente y falseador de las realidades humanas. Habermas continúa actualmente la crítica del método científico y la elucidación de la lógica propia de las ciencias sociales (Sobre la Lógica de las ciencias sociales, 1970).

Desde la misma tradición cientifica, Hayeck ha hecho una dura crítica tanto al cientifismo naturalista como al historicista (Cientifismo y Estudio de la sociedad, 1972). El éxito de las ciencias na- 
turales produjo una verdadera fascinación en los estudiosos de las ciencias humanas, quienes abandonaron sus procedimientos propios para imitar su paradigma metodológico. Ello condujo a una imitación ficticia de las ciencias naturailes, en perjuicio del auténtico espiritu científico. El historicismo pretendió igualmente establecer las leyes generales de la historia, generalizando por falsa inducción. Sus teorías se basan en paralogismos.

Lo que Hayeck propugna es que las verdades cientificas son válidas solamente en los límites de validez de los conceptos que han permitido establecerlas, tanto si se trata de las ciencias naturales como si se trata de las humanas. Cualquier extensión que supere esos límites es ideológica, no científica. En efecto, ningún estudio científico puede abarcar la totalidad de los fenómenos observables; inevitablemente debe operar una selección. Por tanto, los resultados serán válidos en los límites de dicha selección. La ciencia trabaja con modelos elaborados sobre la realidad, no con la realioad misma. De aquí se siguen estas consecuencias: a) no se da propiamente un saber universal, dada la finitud de conceptos con que necesariamente operamos; b) la mayor parte de los conceptos utilizados en las ciencias humanas son construcciones intelectuales, no datos empíricos; no tiene sentido, pues, emplearlos como unidades naturales; c) tampoco tiene sentido utilizar tales conjuntos como si estuvieran dotados de conciencia en sí mismos; en realidad son modelos o tipos ideales elaborados por el antropólogo; por lo demás, las actividades humanas pueden ser conscientes o no; d) finalmente, el antropólogo -como el sociólogo- no debe pretender convertirse en director de la historia; la finalidad de la ciencia no es transformar la realidad, sino conocerla; la modificación de la realidad corresponde al político.

La diferencia de las ciencias humanas respecto de las naturales está en que aquellas se ocupan de relaciones entre hombre y / o entre hombres y cosas; de ahí que el especialista de ciencias humanas no se ocupa sólo de los hechos objetivos, sino también de opiniones, creencias y significados.

\section{i) La razón estructuralista.}

La metodología estructuralista en su aplicación a las ciencias humanas -Lévi-Straus, Lacan, Foucault, Althusser, Barthes - se apoya sobre este denominador común: $1 .^{\circ}$, si las ciencias humanas quieren alcanzar su madurez y ser verdaderamente ciencias han de llegar a formular leyes generales, bien por inducción, bien por de- 
ducción lógica;.$^{\circ}$, para ello sólo tienen que seguir la metodología operativa a ejemplo de la más adelantada de las ciencias humanas, la lingüística estructural. Ello implica la trasposición de dicho modelo a las demás. Lévi-Strauss realizó esta trasposición sucesivamente al estudio del parentesco, del mito, del arte, del pensamiento, del ritual, etc., y estableció la base teórica de la misma (Anthropologie structurale, 1958). El concepto de estructura-modelo le permite superar tanto el realismo ingenuo como el formalismo puro, ya que no se refiere a la realidad empírica, sino a modelos construidos de acuerdo con ésta (mediante la modelización de las relaciones sociales en la estructura social). Dichos modelos serán "mecánicos" cuando se encuentran en la misma escala de los fenómenos y "estadísticos" cuando se trate de una escala diferente. En cualquier caso, el enfoque dado a las ciencias humanas es exclusivamente nomotético.

Indudablemente, el estructuralismo ha aportado una metodología rigurosa y ha corregido los excesos del humanismo, del psicologismo, del historicismo y hasta de la dialéctica. Pero su pretensión imperialista to ha desvirtuado. En primer lugar, porque la metodología estructural se aplica propiamente sólo sobre objetos homogéneos y bien definidos, mientras que se le escapa lo históricodialéctico. En segundo lugar, porque la trasposición de modelos de una disciplina a otra exige resolver previamente delicados problemas de homogeneidad, equivalencias, etc. Lévi-Strauss ha pretendido resolverlo mediante una progresiva formalización del concepto de estructura primero, y mediante su naturalización y generalización después. De este modo la metodología estructuralista se ha revelado como un nuevo lecho de Procusto, que no respeta la especificidad del objeto de las ciencias humanas.

\section{j) El interdisciplinarismo.}

J. Piaget ha presentado recientemente un nuevo intento de colaboración entre las ciencias naturales y las ciencias humanas en base a una nueva actitud epistemológica: el interdisciplinarismo (Epistemologie des sciences de l'homme, 1970). En primer lugar, debe darse una colaboración interdisciplinar entre las ciencias exactas y las naturales. En segundo lugar, se da de hecho una convergencia de problemas en el seno de las ciencias del hombre, en base a su parentesco relativo con las ciencias de la vida. De hecho, las tres cuestiones más centrales y especificas de las ciencias biológicas son la evolución, la organización, los intercambios entre el organis- 
mo y el medio. Pues bien, esas mismas son las cuestiones principales que se plantean en cada una de las ciencias del hombre, aunque sea a escala humana. Las soluciones en ambos niveles se consiguen mediante tres conceptos-clave: estructuras, funciones y significaciones. Pero las ciencias del hombre han desarrollado particularmente la significación mediante tres conceptos específicos propios: reglas, valores y signos. Precisamente, Piaget realiza una interpretación del estructuralismo en sentido genético y en base a la actual teoría de la información, al que presenta como una auténtica solución interdisciplinar.

¿Qué pensar de esta interminable polémica? Constatemos algunos puntos clarificados: a) la crítica del prejuicio naturalista parece consolidada: el criterio epistemológico de las ciencias físicas y naturales no tiene por qué ser considerado como criterio científco universal;; b) la distinción rígida entre las ciencias naturales y las ciencias humanas en base a su diferente metodología se ha mostrado inconsistente. En ambas intervienen hipótesis y modelos operatorios, aunque cada cual tenga su procedimiento específico de verificación a partir de las exigencias de su objeto; c) la oposición objetividad-subjetividad carece de fundamento. Las ciencias humanas estudian la cultura o el comportamiento humano en cuanto formas, procesos o instituciones observables empiricamente; se trata de realidades concretas y objetivas, situadas espacial e históricamente; d) carece de sentido presentar competitivamente ambos tipos de ciencia. Lo propio de toda ciencia es la inteligibilidad de 10 real. Pero esta inteligibilidad puede efectuarse desde diferentes puntos de vista. La unidad de la ciencia no se contradice con la pluralidad de las ciencias. Por otra parte, la especificidad de los objetos de estudio obliga a una adaptación del método al objeto, no del objeto al método; e) por último, cabe señalar que la constitución de una ciencia depende de la solidez de sus resultados, no de las reglas metodológicas. Los modelos científicos son también históricos y dependen del mismo avance de la ciencia. No tiene sentido hipostasiar a ninguno en base a su vigencia en un tiempo y en un ámbito concretos y particulares (Kuhn).

\section{2. LA ANTROPOLOGIA Y LAS CIENCIAS HUMANAS: DEMARCACION $Y$ RELACIONES}

Para hablar con precisión de antropología se hace preciso deshacer previamente algunos equívocos. En primer lugar, sobre su 
contenido $u$ objeto propio. En la Europa continental por antropología se entiende, en principio, antropología física; de los aspectos culturales y sociales se ocupa otra disciplina: la etnología. En Inglaterra, en cambio, antropología suena, ante todo, como antropología social; los aspectos físicos se reservan a la paleontología y a la genética; los culturales, a la arqueología y a la historia. Por último, en Estados Unidos antropología es preferentemente antropología cultural, que incluye algunos capítulos de peleontología humana y de genética. En segundo lugar, sobre su ubicación precisa. Se distingue, al respecto, entre ciencias humanas y ciencias sociales, entre ciencias humanas y ciencias del hombre; finalmente, entre antropologia y ciencias humanas y/o ciencias del hombre. Examinemos primeramente este segundo punto.

La distinción entre ciencias humanas y ciencias sociales surgió a primeros de siglo en Estados Unidos de un modo bastante artificial. De hecho, la distinción arraigó a nivel de instituciones, en el que persiste hasta hoy e incluso se ha generalizado. Pero resulta difícil de sostener en rigor científico. Redfield en Norteamérica y Evans-Pritchard en Inglaterra criticaron de modo convincente tal distinción: ni lo humano es accesible sin lo social, ni lo social sin lo humano. Unicamente cabe a efectos de clasificación de disciplinas o, simplemente, de matiz. La distinción entre ciencias humanas y ciencias del hombre no puede tener más sentido que el de una preferencia de terminologia: a ciertos autores la denominación ciencias "del hombre" les parece más concreta que la genérica y abstracta "humanas". La distinción entre antropologia y ciencias humanas/ciencias del hombre posee, en cambio, plena vigencia y debe ser examinada cuidadosamente. Tanto más cuanto que con ello resolveremos también conjuntamente el primer equívoco apuntado.

El término antropología (del griego "anthropos", hombre, y "logos", tratado) hace referencia al estudio del hombre. Indudablemente, se refiere al hombre en general, en todas sus formas de sociedad, de cultura y de naturaleza:

-su naturaleza biológica: genes, caracteres raciales y sexuales etc.;

$\rightarrow$ su historia: orígenes, evolución, cambios socioculturales, etc.;

-sus productos: técnicas, instrumentos, evolución cultural, etc.;

- sus comportamientos colectivos en la totalidad de las sociedades pasadas y actuales, en el espacio y en el tiempo;

- el hombre personal como producto y productor de la cultura, etc. 
Como es lógico, cabe preguntarse por la viabilidad de una ciencia con un objeto tan complejo y tan poco definido. La metodologia propia de las ciencias naturales comienza por exigir un objeto homogéneo y bien definido. Pero no debemos mezclar ambas cuestiones ni prejuzgar de antemano los planteamientos. Porque lo cierto es que nos hallamos ante un objeto real: el hombre. Por tanto, en principio no sólo cabe, sino que es preciso que se ocupe del mismo alguna disciplina especifica. La antropologia, pues, en principio no sólo es legítima, sino que es necesaria. Ahora bien, el hecho de que el objeto hombre se nos presente como sumamente complejo y polivalente pertenece a la realidad del objeto y debe ser asumida como tal, aunque ello ofrezca dificultades de orden epistemológico. Pero ésta es ya otra cuestión que estudiaremos más tarde. Baste decir por ahora que no es el método quien decide el objeto, sino que es el objeto el que exige un método adecuado para el estudio de tal objeto, con sus peculiaridades propias. Lo contrario sería caer en la aporía del método, tantas veces denunciada.

Quedamos, por tanto, en que el objeto de la antropología es el hombre en su compleja realidad biológica-histórica-cultural-social. Otra cosa es que, lógicamente, un objeto tan inmenso se halla fragmentado en aspectos específicos y particulares para hacerse objetos de toda una serie de antropologias "regionales" o parciales, que se ocupan de determinado aspecto o nivel del hombre. Destaquemos entre ellas las siguientes:

a) Antropología física o biológica: predominante en el continente europeo. Esta disciplina se ocupa del hombre en cuanto organismo físico-biológico, investiga su posición en el cuadro de la evolución biológica y diferencia los diversos grupos raciales. Para ello ha desarrollado varias disciplinas auxiliares como la genética y la paleontología humanas, la taxonomia racial (el hombre como especie politípica y polimórfica), la ecología humana (los problemas de adaptación al medio, el habitat y los ecosistemas), etc. Otras disciplinas auxiliares son todavía menos específicamente humanas, como la estadística, la primatología, mediciones osteológicas, geología, etc.

b) Antropología cultural, etnografía y etnologia: durante mucho tiempo se han utilizado estas denominaciones como sinónimas; la primera, preferentemente en Norteamérica; las otras dos, en Europa continental. Hoy predomina el nombre de antropología cultural también en Europa. La etnografía se refiere a la simple descripción de las sociedades humanas, en especial de las más simples. Corres- 
ponde, pues, a la primera etapa de investigación: observación y descripción, trabajo sobre el terreno o trabajo de campo, con sus técnicas propias. Incluye igualmente la clasificación, descripción y análisis de fenómenos culturales particulares. La etnografía puede realizarse también en un buen museo.

La etnología, en cambio, presenta una ambigüedad considerable. En el pasado se entendió como equivalente de antropología. Hoy, sin embargo, se observan dos tendencias: los anglosajones la entienden como estudio de los pueblos ágrafos y de sus productos culturales. Propiamente se ocuparía más de reconstruir el pasado que de interpretar el presente. Supone una segunda etapa sobre la etnografía, un primer paso hacia la sintesis explicativa general (tal es el sentido del "Bureau of American Ethnology" y del "Institut d'Ethnologie" de Paris). Para los europeos, sin embargo, tal denominación está siendo suplantada simplemente por la de antropología cultural, que se ocupa tanto del pasado como del presente de las sociedades humanas, al igual que de sus caracteres rurales, urbanos, tradicionales, industriales, etc. En principio, la antropología cultural se ocupa de una sociedad concreta y la estudia exhaustivamente; sólo secundariamente aspira a un conocimiento aplicable al conjunto de la humanidad, con la excepción del estructuralismo antropológico, que se orienta directamente a establecer leyes universales del hombre.

c) Antropología social y antropología cultural: Aunque Murdock y Firth sostuvieron hace un cuarto de siglo una enconada polémica respecto de la delimitación precisa de ambas denominaciones, lo cierto es que hoy ambas tienden a ser consideradas equivalentes; simplemente, los británicos prefieren la primera; los demás, la segunda. Los motivos de la misma son meramente locales. De hecho, los términos "social" y "cultural" se referían al mismo concepto, hasta que Radcliffe-Brown concretó el objeto de la antropología en el estudio de la estructura social. Desde entonces, los antropólogos británicos se han ocupado preferentemente de los aspectos sociales, políticos, económicos, relaciones de parentesco, dejando en segundo término los mitos, el ritual, el arte, las técnicas, etc. Pero se trata más bien de una especialización dentro del amplísimo campo de la antropología cultural que de una verdadera diferenciación. En Francia comienza a imponerse también la denominación de antropologia social, pero con idéntico sentido que la cultural.

d) Antropología filosófica: en sus orígenes, la antropología filosófica se presentó como la parte de la filosofía especulativa que 
se ocupaba del hombre, entendido preferentemente como espiritu pensante: psicología racional. Con Dilthey, Scheler y otros pensadores se presentó ya como una reflexión sobre los datos biológicos y culturales que ofrecian las antropologias cientificas; se trataba de formular una teoria unitaria y abstracta sobre el hombre universal. En la actualidad esta disciplina se limita a ser reflexión globalizante sobre los resultados obtenidos por las ciencias del hombre para elaborar teorías particulares sobre el hombre, a la espera de poder formular algún dia una teoría general. Aunque el valor de tales teorías es desestimado sistemáticamente por muchos antropólogos, debe tenerse en cuenta que la reflexión antropológica se sitúa a un nivel más general que el de las investigaciones concretas y su validez depende únicamente de que tanto la reflexión como la teoria se ajusten a las leyes de la lógica. En el peor de los casos, se podrá desestimar su relevancia cognoscitiva, pero nunca puede negarse por principio su legitimidad. La reflexión filosófica no interfiere la teoría científica pues, por definición, se sitúa en otro nivel y se ajusta a un estatuto epistemológico autónomo; esto es, posee sus propias condiciones de validez.

Otras disciplinas antropológicas particulares son: arqueología, antropometría, linguiistica, tecnología, mitología, morfologia humana, etc.

Lo que queda claro, en definitiva, es que las diversas ciencias del hombre se ocupan de aspectos parciales y que las diferentes antropologías (física, cultural, fllosófica) se aplican al estudio de 10 humano tras operar una delimitación del campo y del nivel epistemológico. ¿Cuál es, pues, el sentido de una antropología general en cuanto "la" ciencia del hombre? Justamente, si existen las antropologías regionales ha de existir también la antropología general. $\mathrm{Su}$ objeto específico: el estudio del género homo como una totalidad. Se trata de estudiar sistemáticamente al hombre en cuanto naturaleza, cultura y sociedad, sus manifestaciones y actividades. Pero tal ciencia genérica puede tener sentido solamente con dos condiciones:

-que cuente de antemano con las investigaciones y resultados' de las antropologias regionales y demás ciencias del hombre;

-que se enfatice la noción de sistema: ningún aspecto o nivel del hombre puede ser entendido correctamente fuera del todo.

-Justamente, esta visión sistemática es la aportación fundamental de la antropología general. 
Ahora bien, ¿cómo se hace posible una sintesis tal? Advirtamos de antemano que no se trata de hacer una sintesis definitiva; al contrario, se trata de hacer una sintesis incesante, pero siempre provisional, paralela a las investigaciones de las antropologias regionales; lo propio de la antropologia general es aportar incesantemente el punto de vista sistemático. Hoebel y Cencillo, entre otros, han presentado metodologías a este propósito:

a) Hoebbel: los niveles sucesivos de generalización antropológica $^{4}$. Nuestro autor clasifica las diferentes ciencias del hombre $y$ antropologías regionales en relación con los diversos niveles de investigación científica, to que da lugar a cuatro niveles de generalización:

Nivel 1: observación empírica y clasificación general: la antropometría, la arqueología y la etnografía observan y clasifican los hechos primarios de las poblaciones humanas y de las culturas prehistóricas y recientes. Nivel empírico.

Nivel 2: clasificación y análisis especializados de los subsistemas: los especialistas formulan y ponen a prueba generalizaciones limitadas y parciales en las siguientes áreas de estudio: biología humana, morfología y paleontología humanas, tecnología, mitología, lingüística, etc. Se estudian aspectos limitados del hombre o sus obras que constituyen subsistemas.

Nivel 3: análisis generalizador de los sistemas biológicos y culturales: el antropólogo físico y el antropólogo cultural realizan las sintesis de sus respectivas antropologías regionales a nivel de sistema; ello exige la elaboración y puesta a prueba de las generalizaciones biológicas y cultural en base a los hallazgos de los especialistas del segundo nivel de las ciencias del hombre.

Nivel 4: ciencia integradora del hombre: en este nivel el antropólogo general sintetiza y unifica en un sistema de superior generalidad y abstración los resultados de la antropología física y cultural. Con lo que se realiza una interpretación universal del hombre y de sus producciones.

b) Cencillo: integración de los diferentes niveles en una antropología integral ${ }^{5}$. Se dan saberes acerca del hombre en los que 6-10.

4. E. A. HOEBBEL, Antropología. El estudio del hombre (Barcelona 1973) 42.

5. L. CENCILLO, Curso de antropología integral (Madrid 1970) 11-12 y 39- 
éste viene a ser estudiado como una serie más de procesos biologicos, fisiológicos, económicos y sociológicos, a niveles perfectamente prescindidos, sin implicaciones de otro tipo que aquellas toleradas por el nivel correspondiente, mas por lo mismo no es el hombre en cuanto humano lo que estas ciencias estudian, sino en cuanto mero fenómeno biológico, económico o social, en igual plano que los demás seres vivos que participan en estas series de fenómenos.

Pero la antropología no es un saber de este tipo; aunque no deja de ser un saber perfectamente positivo, su objeto formal no se agota en uno solo de aquellos niveles, sino que es implicativo $e$ integral: su modo de positividad y su intención epistemológica consisten precisamente en la integración de todos ellos en una consideración metódica común. Su objeto formal no es el hombre en cuanto conjunto de fenómenos biológicos, económicos o sociales, sino el hombre en cuanto humano, en cuanto un viviente de tal naturaleza específica que integra todos los niveles posibles que le afecten en una peculiar unidad dinámica de modalidad propiamente humana. Incluso aquellos aspectos más neutros, como el genético, al hallarse integrados en el todo de un saber acerca del hombre en cuanto tal, presenta una vertiente de problematicidad transbiológica que le comunica su carácter específicamente antropológico. La corriente estructuralista ha pretendido justamente neutralizar epistemológicamente al hombre en cuanto hombre para liberarse de los problemas inherentes a las ciencias humanas: pero se trata de un esfuerzo fallido, pues la experiencia del sujeto humano que hace ciencia no deja de enredárseles constantemente en todos los niveles de su refiexión, a pesar suyo.

Ciertamente, el objeto de estudio de la antropología, el hombre, es una realidad multivalente y ambigua. Ni se agota en lo medible, ni es propiamente perceptible ni controlable en sus niveles más profundos, ni se da jamás como algo definido de una vez para siempre. De ahi que sea legitimo distinguir varios niveles y especializaciones dentro de la antropología:

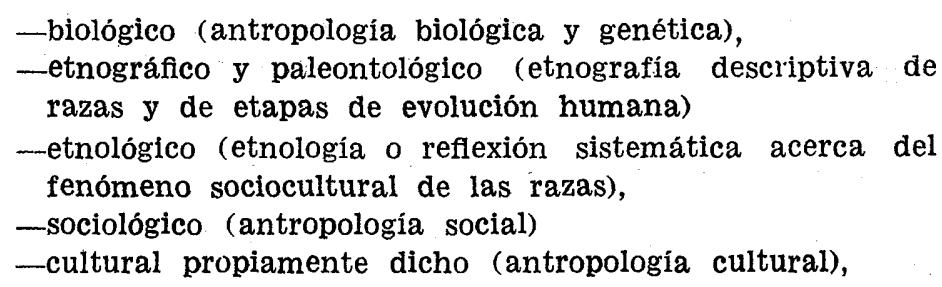




\section{-psicológico (antropologia psicológica) \\ - psicoanalítico (antropologia psicoanalítica) \\ -filosófico (antropología filosófica).}

Nuestro autor piensa que estos niveles han de integrarse en una Antropología que pretenda hacerse cargo de la realidad humana en su totalidad. Cada rama de la antropología que estudia cada uno de los niveles citados está plenamente justificada y cuenta con métodos específicos, exigidos por la positividad de su correspondiente objeto formal. Pero si la antropologia ha de ser la ciencia-delhombre ha de integrarlos todos en una síntesis epistemológica capaz de hacerse cargo lúcida y controladamente de su complejo objeto 6 .

En definitiva, si la antropología ha de ser ciencia y no el camuflaje de una ideologia, debe respetar las dimensiones y niveles de su propio objeto total y no tender a parcializarlo desde uno $u$ otro nivel hipertrofiado. Su método ha de estar, en principio, constituido por los métodos propios de cada dimensión y nivel; inclúso del último citado, el filosófico. Pues la naturaleza inconmensurable e indefinita (nunca plenamente positivable ni sincrónicamente captable) de su objeto, pide una consideración total que rebase el orden de los meros datos materiales y fenoménicos.

Esta metodología propuesta por Cencillo para la integración de las ciencias del hombre y de las antropologías en una antropología general no parece tan clara ni convincente como la de Hoebbel por lo que respecta a los diferentes niveles de generalización, que no son expresamente distinguidos; pero presenta el mérito de enfatizar que la valencia propiamente humana se deriva justamente del sistema total que es posible lograr únicamente mediante la antropología general.

A mi entender, la antropología general, además de su esfuerzo sintetizador --siempre provisional e inconcluso, claro está-, por elaborar una teoria del hombre, cumple también otras funciones in.sustituibles, que podriamos resumir en los siguientes puntos: $10^{\circ}$ ) En base precisamente a su esfuerzo sistematizador, la antropología general o filosófica realiza una critica incesante de las teorias formuladas en los niveles dos y tres; su visión de conjunto le permite captar determinados desenfoques o acentuaciones unilaterales en las teorías concretas. En este sentido, la antropología realiza también

6. L. CENCILLO, Curso de antropologia integral, 13. 
una función de control experimental indirecto, pero eficaz. $2 .^{\circ}$ ) $\mathrm{Al}$ mismo tiempo, la antropologia formula incesantemente ciertas hipótesis y teorias que presenta para su verificación a los especialistas de la antropología biológica, cultural y social; de este modo, se ofrece como un poderoso estimulador de investigaciones concretas; 3.') Junto a esta función crítica y estimulante de la investigación positiva la antropologia general cumple también otra función utópica, mediante la cual intenta responder a las cuestiones radicales y permanentes que los hombres demandan de las ciencias humanas: ¿es posible la libertad en sociedad?; ¿son todos los hombres iguales?; ¿es el hombre un ser agresivo o más bien cooperativo?; ¿existen unos universales éticos?, etc. Las respuestas han de ser forzosamente provisionales y limitadas, pero en modo alguno carecen de relevancia.

Por lo que respecta a las relaciones internas entre las diversas ciencias humanas, el propio Hoebbel nos ofrece un esquema, que hemos modificado en base a sustituir el núcleo "ciencia" por el de "sociedad", y situar la "antropología general" en el centro del cuadro:

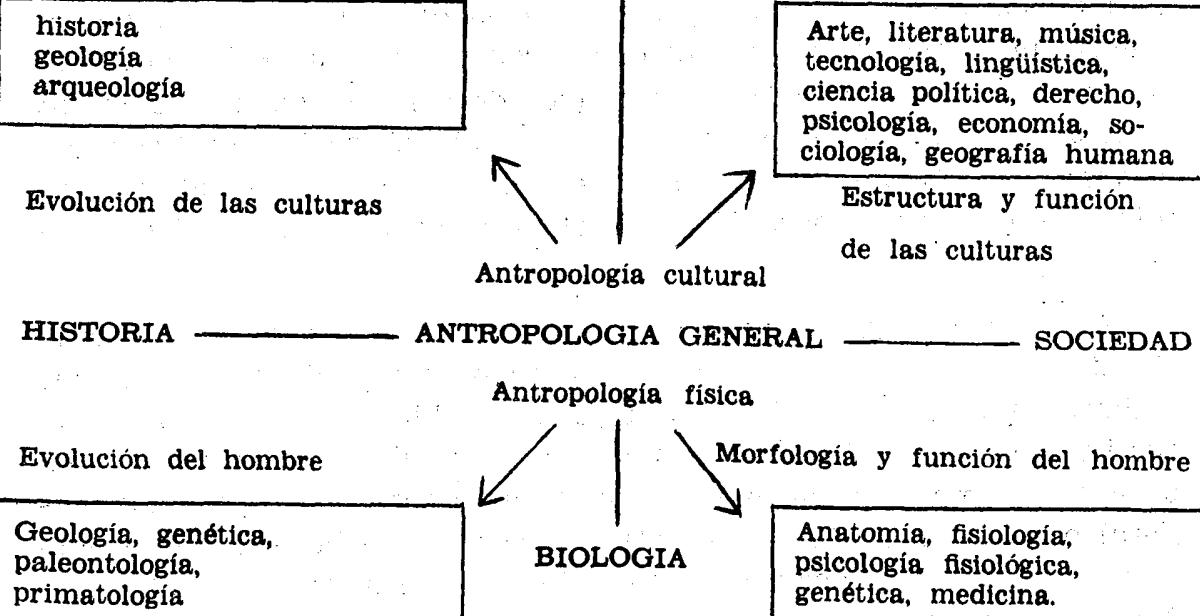

Antropologia cultural

HISTORIA ANTROPOLOGIA GENERAL SOCIEDAD

Evolución del hombre

Geología, genética, paleontología,

Antropología física

primatología

CULTURA 


\subsection{ESTATUTO EPISTEMOLOGICO DE LA ANTROPOLOGIA}

¿Puede hablarse de una ciencia antropológica? ¿Puede ser considerada la antropologia una verdadera ciencia? Tras lo que llevamos expuesto, sobre todo en el parágrafo primero, la respuesta es claramente afirmativa. Pero decir que la antropologia es una ciencia no pasa de ser una generalidad; lo importante es definir el estatuto epistemológico que le es propio de acuerdo con las características de su objeto. En efecto, las exigencias del objeto son lo primero; las exigencias del método científico deben adaptarse a cada objeto de investigación. De lo contrario caeríamos en la paradoja del método: lo que por naturaleza está destinado a facilitar o simplemente guiar la investigación impondría sus condiciones al objeto que tratamos de investigar; pero es obvio que el método debe subordinarse al objeto. Pese a todo, esta paradoja del método se produce con demasiada frecuencia en nuestro tiempo, quizá porque se ha puesto excesivo énfasis en la cuestión metodológica.

En realidad, el concepto de ciencia se ha constituido históricamente. Con los griegos era un saber definitivamente cierto y demostrado, pues se obtenía a partir de las causas del fenómeno objeto de estudio; con Descartes, sin embargo, se consideraba científico el saber inmediato, claro y distinto. Hoy se entiende por científico el saber positivo metódicamente controlado y sistemáticamente organizado. El saber ha de ser positivo, es decir, adquirido por observación objetiva, directa o mediante instrumentos, según una hipótesis. Metódicamente controlado, es decir, según procedimientos de medida y cálculo (matemáticos). Pero es preciso tener en cuenta el estatuto epistemológico de la cuantificación: no tiene valor en sí misma, sino en cuanto que es un procedimiento de control operativo-dinámico, que organiza de modo preciso los datos de la observación y posibilita ulteriores operaciones de cálculo; pero es obvio que la ciencia no se agota en la calculabilidad. Finalmente, se exige que ese saber sea organizado sistemáticamente, es decir, en un sistema o teoría coherente que permita, si es posible, la formulación de leyes generales. También suele exigirse una representación matemática o lógico-formal. Pero esta exigencia es típica de las ciencias exactas y físicas. Igualmente, toda ciencia se sirve de técnicas de observación (en laboratorio o sobre el terreno), de procedimientos experimentales (cuando son posibles; si no; cabe el recurso a experimentación indirecta o incluso "post factum", si es posible controlar algunas variables) y de teorías o modelos (elaborados a partir de los hechos, pero independientes de los mismos, convencionales, 
operatorios). Se distinguen también diferentes niveles de generalización o etapas a través de las que el científico procede a formulaciones cada vez más generales.

Las caracteristicas propias del hombre -objeto de la antropologia - obligan a un reajuste casi general de la metodología científica para adaptarla a sus exigencias, de modo que sin dejar de ser científico, el método haga justicia al objeto. Aqui se aprecia justamente la necesidad de establecer el estatuto epistemológico propio de la antropología como ciencia. En efecto, es preciso resolver convenientemente toda una serie de aporías derivadas de la ambigüedad e indefinitud del hombre:

a) la investigación científica se realiza sobre un objeto heterogéneo (multidimensional) y ambiguo (equívoco). Este problema, que parece imposibilitar el carácter científico de la antropologia, se soluciona adecuadamente en base a los diferentes niveles de generalización científica ya expuestos con anterioridad. El nivel cuatro en que se mueve la antropología general supone previamente los niveles tres, dos y uno. Ahora bien, a nivel uno y dos, los aspectos concretos del hombre que estudian las ciencias humanas son suficientemente homogéneos y exentos de equivocidad en su definición. Por tanto, todo el problema se reduce a realizar una correcta generalización a nivel cuatro conforme a las leyes de lá lógica.

b) el hombre como sistema total o integral no es cuantificable en sentido estricto; en efecto, lo humano no se agota en un conjunto de medidas, que sólo acceden a aspectos parciales y externos. Esta aporía admite dos soluciones relativas. En primer lugar, a nivel uno y dos es posible realizar casi siempre una cuantificación suficiente; cuando no es posible, quedan todavía los procedimientos indirectos o derivados; e, incluso, cabe apelar a procedimientos de evaluación (cualitativos) suficientemente contrastados. En efecto, los productos culturales del hombre (arte, mitos, etc.) y sus instituciones son algo perfectamente objetivo y accesible a la observación. En segundo lugar, es cierto que en antropología, como en las ciencias humanas en general, el investigador debe limitarse a observar situaciones existentes más bien que situaciones procuradas experimentalmente. Pero cabe decir que el procedimiento experimental propio de las ciencias humanas es una combinación del trabajo de campo (observación participante) con el método comparativo (cualquier generalización se hace en una perspectiva intercultural). Intentar la experimentación estricta en antropologia seria falsear el objeto. 
c) toda ciencia persigue elaborar modelos y leyes universales; pero el hombre es, primordialmente, un ser singular, diacrónico (se hace en el tiempo) y sujeto al cambio sociocultural. No parece posible establecer ningún tipo de leyes universales sobre el hombre, por tanto. Esta objeción tiene una relevancia indudable y debe estudiarse cuidadosamente. Responde a las justas inquietudes de la escuela de Baden (Windelband, Rickert), que les llevó a distinguir entre ciencias "nomotéticas" y ciencias "ideográficas", las primeras orientadas a establecer leyes universales, las segundas atentas a estudiar el objeto en su singularidad histórica y cultural. Pero ya vimos que, propiamente, ambos tipos de ciencias no se oponen en virtud de su objeto, sino más bien de su orientación preferente. Ello quiere decir que la generalización antropológica debe hacer igual justicia a la exigencia nomotética como a la ideográfica. Aquí converge también la objeción del relativismo absoluto. Pero este relativismo absoluto se desacredita en su misma formulación. El hombre es un ser singular, pero también es un ser genérico; la variación intercultural es real, pero también lo son los universales culturales.

d) por último, en toda ciencia el sujeto es independiente del objeto que estudia; al mismo tiempo, sujeto y objeto se hallan sobre la misma escala de magnitud (de lo contrario es necesario apelar a los instrumentos que la corrigen), pero se encuentran convenientemente distanciados (distancia de observación objetiva). En las ciencias del hombre en general se produce, pues, una doble distorsión del campo semántico:

1. La perturbación subjetiva que el observador introduce en lo observado. Parece inevitable que en toda investigación antropológica se dé siempre un coeficiente de subjetividad, por parte del sujeto, y de opcionalidad, por parte del objeto. Se plantea aqui el complejo problema de las ideologías, las interferencias producidas por los prejuicios, los intereses de todo tipo, los gustos, etc., que amenazan viciar de raíz toda investigación;

2. ${ }^{a} \quad$ En la antropología, objeto y sujeto están en la misma escala. No se produce, pues, la distorsión macroscópica (como en la astrofísica: el observador es cogido y modificado por el fenómeno estudiado), ni la distorsión microfísica (la acción del experimentador modifica el fenómeno observado); en ambos casos se precisan instrumentos adecuados que corrigen la distorsión producida por la diferencia de escala entre el observador y lo observado. Pero se da la distorsión de la identificación entre el sujeto y el objeto. En las 
ciencias del hombre, al ocuparse de los aspectos particulares como el lenguaje, el proceso económico, etc., esta distorsión es solamente parcial. Pero en la antropología general la distorsión se hace total, por su mismo planteamiento globalizante: la coincidencia sujetoobjeto impide el distanciamiento preciso para una observación objetiva.

¿Qué solución cabe para preservar la cualidad científica de la antropologia ante esta doble distorsión de su campo semántico? Según algunos, esta situación descarta a la antropologia de un estatuto propiamente científico; incluso las ciencias del hombre serán siempre un tipo de ciencia muy "sui generis", de validez particularmente provisional y limitada; pero la antropología como tal debe ser entendida como un ejercicio filosófico, sino ya como mero ensayo literario. Para otros no quedan más opción que limitarse a las ciencias del hombre, con sus estudios parciales y regionales: aquellos aspectos del objeto que permitan un tratamiento científico. Por otra parte, los enfoques estructuralistas se proponen reducir la ambigüedad del objeto y anular la subjetividad mediante procedimientos formales, aunque con el riesgo de eliminar conjuntamente la vertiente de singularidad y especificidad de lo humano.

Sin embargo, pensamos que cabe mantener el estatuto científico de la antropología en base a las directrices antes apuntadas: no es correcto pretender adaptar el objeto de la antropología a la metodologia científica; al contrario, 10 correcto es adaptar la metodología científica a la antropología y respetar su estatuto epistemológico propio. Por esta vía es preciso comenzar por aceptar la peculiaridad de su objeto, asumir igualmente los problemas que plantea su circulación con el sujeto investigador y procurar resolverlos con la ayuda de procedimientos formales limitados, que no anulen de antemano la originalidad de lo humano. Estos aspectos los estudiaremos con algún detalle en el próximo parágrafo. Baste decir ahora que la antropología posee dos vias propias de solución:

1. ${ }^{a}$ Enfoque intercultural: el antropólogo estudia al hombre en una perspectiva intercultural. La revolución antropológica consistió no sólo en el descubrimiento trascendental de la humanidad; sino también en el estudio preferente del hombre en las sociedades de las que el antropólogo no formaba parte. La superación del etnocentrismo permitió resolver conjuntamente varios problemas. Lo humano nos aparece ahora desplegándose en multitud de formas y maneras en la infinidad de sociedades humanas que han florecido en el tiempo y en el espacio; ninguna sociedad puede pretender po- 
seer la exclusiva del hombre; por el contrario, las diferentes sociedades han actuado al modo de un inmenso laboratorio experimental en el que se ha ensayado de forma casi exhaustiva las diversas variables y variantes de lo humano. Ello le ha permitido simultáneamente al antropólogo encontrar el necesario distanciamiento respecto de su sociedad y de su cultura de origen. Aunque también es preciso reconocer que todavía falta por resolver de modo adecuado los nuevos problemas que suscita la introducción de instrumentos mentales (categorias, pautas, ideologias) procedentes de una cultura extraña que; como es lógico, también distorsionan el objeto. Ello puede resolverse mediante la segunda vía:

2. Elaboración de una antropología del conocimiento. Del mismo modo que la sociología ha buscado la solución de sus técnicas de pensamiento mediante la sociología del conocimiento, la antropología debe realizar una operación paralela mediante una antropología del conocimiento. Esta operación reviste una dificultad muy superior al tener que realizarse en una perspectiva intercultural No obstante, se han producido ya los intentos pioneros de Lévy-Bruhl y Lévi-Strauss. Mientras se realiza esta compleja tarea, el antropólogo puede apelar a los procedimientos vigentes en psicología y en sociología para controlar los factores ideológicos y emotivos propios del investigador, a la vez que asume la heterogeneidad de su objete mediante un modelo antropológico comprensivo; en el que los enfoques nomotético e ideográfico se complementen. Pese a todo, es lógico que el antropólogo actual tenga una clara conciencia de las condiciones y de los límites de validez tan restringidos de las teorias que formule.

No obstante, nos permitimos insistir en que esta situación epistemológica no rebaja la calidad científica de la antropologia. También las ciencias físicas y naturales tienen sus propios condicionamientos que resuelven de modo provisional. El investigador de las ciencias humanas debe dejar a un lado su inveterado complejo de inferioridad respecto de aquellas, totalmente injustificado.

\section{d) La superación del humanismo y del etnocentrismo.}

La teoría antropológica se ha venido elaborando en un doble marco racionalista: primero en la tradición cartesiana, dominante en el siglo XVII hasta la segunda mitad del siglo XIX; y que se prolonga hasta hoy en la escuela fenomenológica; segundo, en la reacción anti-idealista, en sus diversas formas (Nietzsche, Kierkegaard, Marx, Dilthey, etc.). La primera había surgido como reacción fren- 
te al objetivismo de la filosofía aristotélico-escolástica; la segunda como reacción, a su vez, frente al racionalismo -individual o trascendental - absoluto en que habia desembocado la herencia de Descartes; igualmente, por efecto de la ley del péndulo, la reacción anti-idealista absolutizó los aspectos no-racionales (activo-volitivos) y singulares del hombre. Los herederos contemporáneos de ambas reacciones (escuela fenomenológica, existencialismo, neo-marxismo, personalismo cristiano) han fundido, sin embargo, las dos corrientes mediante la elaboración de un humanismo de base, en el que se ha venido inspirando hasta hoy en su casi totalidad hasta hoy la reflexión antropológica.

Las tesis fundamentales de este humanismo podrian resumirse en cinco puntos, aun a riesgo de simplificarlo en exceso:

1. Sustitución del teocentrismo y del logocentrismo por un antropocentrismo. El hombre - como individuo y como especieocupa el lugar o los atributos hasta ahora referidos a Dios o a la Idea.;

2..$^{\circ}$ El hombre es situado por la reflexión antropológica fuera de la naturaleza, independiente de la misma y acentuados los caracteres que lo diferencian del animal. Se enfatiza la trascendencia del hombre respecto del mundo natural.

3. ${ }^{\circ}$ El hombre es concebido, ante todo, como sujeto racional, autoconsciente y libre. Estos principios son matizados diversamente por las diferentes corrientes, pero puede considerarse denominador común de todas.

4. ${ }^{\circ}$ El hombre es considerado como centro de perspectiva y de referencia universal. El antropocentrismo hace del hombre el señor de la historia y el creador de los valores.

5. El hombre es la fuente verdadera de la significación y del sentido. La herencia idealista - la reacción fue propiamente antiracionalista - pesa fuertemente en el neo-humanismo contemporáneo. De ahí también su proclividad al antropomorfismo.

Por supuesto, en el movimiento neo-humanista se distinguen varias corrientes bastante diferenciadas sobre la base común de las tesis generales, aunque enfatizando una $u$ otra más que el resto:

a) Personalismo cristiano. En esta corriente conflujen diversas orientaciones sobre una base humanista de inspiración cristiana; la tesis primera se dulcifica de modo que permanezca a salvo la trascendencia. Las principailes fuentes de inspiración de las tendencias aquí confluyentes son: 
-enraizamiento en la filosofía existencial (Marcel, Le Senne, Lavelle) y fenomenológica (Ricoeur, Escuela de Lovaina). Relevancia epistemológica del hombre en cuanto fuente de significación y creador de valores; quedan obscurecidos, en cambio, sus vertientes científica y tecnológica. Refiexión particular sobre el cuerpo como mediador, sobre el conocimiento amoroso y sobre la comunicación humana y sus problemas.

-enraizamiento en la historia y en la vida social (Mounier, Lacroix): es la fuente más comúnmente conocida como personalismo cristiano. Enfasis sobre el valor supremo de lo personal frente al celectivismo y al individualismo liberal. Sintesis más - menos lograda de motivos cristianos, marxistas y existenciales: el compromiso de la acción, libertad situada (no abstracta ni incondicionada), conversión filosófica, etc. El hombre trasciende el orden natural.

-enraizamiento en el conocimiento científico (Teilhard de Chardin): origen evolutivo integral del hombre. La cosmogénesis como revolución categorial y cosmovisional; la antropogénesis como proceso de humanización personalizadora. Síntesis de motivos cristianos y marxistas en su humanismo progresivo-ascensional. El punto Omega, garantía última del éxito del proceso humanizador personalista.

-enraizamiento en la comunicación personal cósmica (M. Buber). La relación como categoría básica universal. Relación yo-ello (instrumental), relación yo-él (indiferente y jurídica), relación yo-tú a triple nivel: personal-cósmico, personal-humano, personal-Absoluto.

b) Humanismo existencialista (Kierkegaard, Heidegger, Jaspers, Sartre). Primado de lo existencial histórico-evolutivo sobre lo esencial-racional. La reflexión se hace desde el sujeto: los problemas surgen en la propia existencia; en todo caso son problemas humanos, no científicos; ni basta la simple reflexión: se exige el compromiso en la acción concreta. Enfasis en defender lo existencial individual y libre frente al determinismo naturalista, al idealismo, a todas las formas de totalitarismo político-social y al funcionalismo y burocratismo. El hombre es el tema central de la reflexión como sujeto en su cuádruple vertiente: como sujeto concreto, abierto (mundanidad), libre (incondicionado) y autotrascendente.

Respecto al método se dan dos modalidades: $1 .^{a}$, filosofia existencialista (Kierkegaard, Jaspers); mi reflexión es válida única- 
mente para mi, no es generalizable; 2. ${ }^{a}$, filosofía existencial (Heidegger, Sartre): la reflexión sobre mi existencia es una mediación para el conocimiento de la realidad; mi reflexión existencial es, por lo tanto, generalizable.

En su intención profunda el humanismo existencialista se revela - al igual que el personalismo cristiano y el neomarxismouna soteriologia secular, mediante la que se intenta superar las diferentes alienaciones humanas. En el caso del humanismo existencialista se pretende liberar al hombre de su frivola dispersión, de su anonimato colectivo e impersonal, de la "mala fe" de sus convencionalismos, para que asuma una existencia dramática, pero dotada de dignidad y autenticidad.

c) Humanismo marxista (Lūkács, Bloch, Fromm, Gramsci, Garaudy). Apoyánđose en los "Manuscritos de 1844", el neo-márxismo considera como tesis central la liberación del hombre respecto de sus alienaciones (económica, religiosa, política, ideológica, etc.). El medio más idóneo se juzga la lucha de clases mediante la acción revolucionaria del proletariado. El materialismo histórico y dialéctico se interpreta desde la óptica libertaria y creadora del "hombre nuevo", que actúa como sentido de la historia.

Se trata igualmente de un humanismo demiúrgico, pues es el hombre, en cuanto clase proletaria, quien crea los valores y se configura en cuanto creador de sí mismo, humanizador de la naturaleza y socializador de los hombres. También es una soteriología secular: su antiteísmo lo confirma. El materialismo histórico y dialéctico actúan como principios de inteligibilidad de la historia y de la naturaleza, respectivamente.

Por lo demás, confluyen sobre el mismo otros ingredientes de orígenés diversos; así su epistemología de corte científico, que no excluye algunos elementos utópico-escatológicos; su autonomismo ético, sobre el criterio único de la praxis; y, por fin, su idealismo comunitario, pese a las concreciones colectivistas.

d) El estructuralismo como anti-humanismo (Lévi-Strauss, Foucault, Lacan, Althusser): la metodología estructuralista, aunque partía de bases muy diferentes, ha terminado por atacar frontalmente los plateamientos humanistas en antropología. La critica se ha centrado en su antropocentrismo subjetivo, autoconsciente y libertario. Con esta perspectiva, los estudios antropológicos resultaban ser inevitablemente estudios antropomórficos. El subjetivismo incontrolado provocaba una grave distorsión del campo semántico. De ahí la necesidad de un método objetivo -que en la práctica ha 
sido objetivista - que ha comenzado por despojar al hombre de sus atributos humanistas mediante sus principios opuesto:

-el hombre debe ser reintegrado en la naturaleza como "cosa entre cosas";

-el hombre carece de especial relieve epistemológico;

-el hombre es un lugar anónimo donde se reflejan las estructuras cósmicas, biológicas y culturales, sin constricciones.

Una vez más, la ley del péndulo en la historia del pensamiento científico. El hombre objetivizado es, ciertamente, "la muerte del hombre" humanista, pero seguramente, no sólo del concepto humanista del hombre. Examinemos, aunque sea brevemente, la fuerza y debilidad de ambos planteamientos?

Los estructuralismos coinciden en un punto: la denuncia del espejismo producido por la confusión de la conciencia y del sujeto como origen del humanismo racionalista. De hecho, la propia tradición racionalista se ha esforzado por controlar el subjetivismo flagrante de su planteamiento inicial: Kant, Hegel, Husserl, Heidegger, Sartre... intentan de diversos modos trascendentalizar el "cogito" cartesiano. Es la historia de los esfuerzos casi impotentes por recuperar lo que se había perdido ya en el punto de partida a causa de las pretendidas evidencias del yo, con la subsiguiente identificación del sujeto y la conciencia, del yo con el pensamiento racional. Precisamente, los reajustes introducidos perseguian, ante todo, lograr la perfecta coincidencia del sujeto con la coincidencia reflexiva y "suturar" por todos los medios las "brechas", que el mismo análisis filosófico ponía al descubierto.

Pues bien, las ciencias del hombre y, en especial, la antropología, han dependido en exceso de esta tradición racionalista; prisionera de las falsas traspariencias entre el yo y el sentido. Al "¿qué sé yo?" del escéptico Montaigne, creyó poder responder Descartes: "sé que existo, puesto que pienso". Y es que Descartes creía poder pasar directamente de la interioridad de un hombre a la exterioridad del mundo sin ver que entre ambos extremos se sitúan sociedades, civilizaciones, mundos de hombres ${ }^{8}$. La revolución antropológica ha venido a completar el planteamiento del inconsciente freudo-marxista y estructural. La metodología estructuralista recoge la crítica de las ideologías (Marx) y la crítica de la moralidad

7. Para una exposición más amplia y comprensible remito al lector a mi libro: Levi-Strauss. Estructuralismo y ciencias humanas. Madrid, 1976.

8. C. LEVI-STRAUSS, "Jean Jacques Rousseau, fondateur des sciences de l'homme": Anthropologie structurale deux. Paris, 1973. 
(Nietzsche), pero se funda, sobre todo, en el descubrimiento del incosciente y su aplicación particular en la fonología linguiística.

El estructuralismo replantea radicalmente el problema del sujeto sobre la base del inconsciente, que desvincula al sujeto de la conciencia y del sentido, que se le presentan no como "yo", sino como un "él" piensa. En efecto, el psicoanálisis ha mostrado cómo la conciencia es, en principio, "falsa conciencia". Queda desautorizada toda utilización "inmediata" de la conciencia reflexiva, como se hacia habitualmente en el humanismo. Como Descartes dudaba de las cosas, es preciso dudar ahora de la conciencia: hay que comenzar por la crítica de la conciencia y de sus espejismos, ya que nunca nos presenta directamente la verdad.

Ahora bien, para captar este sentido que se oculta es preciso elaborar una nueva epistemologia, que desborda el cuadro teorético de la fenomenología. El mismo psicoanálisis improvisó un aparato conceptual -una metapsicologia - sobre la dinámica funcional ello-yo-superyo, constituyendo tales instancias un sistema, una totalidad. La transparencia de la conciencia se ha convertido en una penosa búsqueda y conquista del sentido sobre el no-sentido, que se encuentra mediante la interpretación, el desciframiento de un código secreto, aunque no absurdo. El sueño, la neurosis, etc., es un "discurso enredado" que el psicoanálisis transcribe en un texto inteligible

$\mathrm{Y}$ es que, como ha mostrado Ricoeur ${ }^{9}$ siguiendo a Merleau-Ponty, el "cogito" cartesiano engloba dos intenciones epistemológicas diferentes: 1) momento apodíctico o juicio tético: "pienso, luego existo"; 2) momento de la adecuación o juicio de la percepción: soy "tal como" me percibo. El primer momento sigue siendo válido e indemne de toda crítica; pero el segundo era abusivo. La existencia del inconsciente obliga a una "arqueología del sujeto", que supone la critica de la consciencia inmediata y de sus espejismos. En efecto, el sujeto, está doblemente mediatizado: por el universo de los signos (semiótica) y por la interpretación sociocultural de tales signos (semántica).

No obstante, el inconsciente sobre el que se construye la metodologia estructuralista no es ya el inconsciente freudiano, sino un inconsciente más universal, objetivo e intercultural: el fonológico y el cibernético (teoría de la información). Como es sabido, el inconsciente fonológico se origina en la distinción establecida por Saussure entre "habla" (acto del sujeto consciente) y "lengua"

9. P. RICOEUR, Le conflit des interprétations (París 1969) 238-240. 
(conjunto de estructuras que determinan las relaciones significante-significad,o, inconsciente). La fonologia estructural ha desarrollado al máximo las consecuencias de esta distinción fundamental, al deducir tres niveles principales, aunque funcionan en la misma totalidad: $10^{\circ}$ eje sincrónico-diacrónico (temporal); $2 .^{\circ}$ eje sintagmático-paradigmático (relacional) y $3 .^{\circ}$, nivel inconsciente de la mente, en el que tienen lugar las síntesis lingüisticas sin la conciencia del sujeto. Como se ve, se trata de un nuevo modelo de inconsciente, cuya dinámica no obedece ya a una "semántica del deseo", sino a las posibilidades operacionales; se revela como un sistema categorial autónomo, que funciona con entera independencia del sujeto consciente. Por otra parte, la moderna teoria de la información ha venido a consolidar este modelo: las actuales "máquinas pensantes" superan netamente las posibilidades operatorias de un psiquismo humano individual.

Este inconsciente categorial autónomo replantea el problema del sentido que los humanistas vinculan enteramente al sujeto individual, consciente y libre. Queda claro que el sentido no depende sólo de tal sujeto, sino también y primeramente de aquel "sentido del sentido", con su modelo universal objetivo. Aunque tampoco queda totalmente independiente del sujeto, como pretende el estructuralismo, pues el sentido siempre aparece vinculado, en última instancia a un sujeto que se lo apropia y lo hace suyo. La lección estructuralista fundamental es ésta: el sentido no es algo inmediato a un sujeto particular, sino que está mediatizado por una semiótica y una semántica interculturales, inconscientes, universales.

Más exactamente todavía, cabe hablar de un "apriori objetivo" (inconsciente estructural) y de un "apriori subjetivo" (sujeto consciente) mediados por un tercer apriori, el "cultural". El apriori objetivo o semiótico (simbólico, restringía Cassirer), no capta directamente la realidad, sino que ésta le llega envuelta en signos, conforme a su propia capacidad de formalización. El mensaje de la realidad le llega, pues, codificado. El lenguaje es sólo un código particularmente refinado y complejo. Pero no puede hablarse de identidad ni de isomorfismo entre el sistema de lo real y el sistema de codificación semiótica, sino más bien de representación o equivalencia. La razón es obvia: el proceso de lo real es contínuo, mientras que la codificación es necesariamente discontinua. Podría aducirse incluso que la percepción es siempre opcional (hablamos sólo de parte de lo real).

Ahora bien, como ya constató el último Saussure, lo semiótico es también producto sociocultural. Además de los universales 
semióticos (apriori objetivo) hay que contar con la semiótica cultural diferencial (apriori cultural), que mediatiza al primero hasta la semiótica decodificadora individual (apriori subjetivo): La semiótica occidental ha seguido elaborándose en buena medida a espaldas de la "revolución antropológica", sobre un supuesto isomórfico intercultural; que ha sido ya claramente desmentido por la investigación etnológica. Tampoco se trata de anclarse sobre un relativismo cultural igualmente superado; se trata, simplemente, de hacer justicia al "apriori cultural", ese inmenso "laboratorio" experimental en el que las sociedades humanas, en el tiempo y en el espacio, ensayan incesantemente su código y su semántica sobre una matriz humana universal.

Vista desde la parte del "apriori subjetivo" o hermenéutica individual aparece igualmente clara la necesidad mediadora del apriori cultural. En efecto, sobre el poder significante del sujeto humano, excesivamente enfatizado por el humanismo, es preciso situar el poder significante del sistema cultural vigente, del que se nutre el sujeto individual aunque lo adopte original y creativamente. $Y$, como se sabe, las diferencias culturales constituyen dominios cognitivos diferentes, con campos sintácticos, semánticos y pragmáticos particulares y específicos.

A la superación del humanismo se une, pues, la superación del etnocentrismo. La semiótica objetiva de los estructuralistas y la semiótica objetiva de los humanistas van mediadas necesariamente por la semiótica cultural (o sociocultural), que ha sido hasta hoy la gran olvidada, tanto en el dominio de los signos como en el especifico del lenguaje y, en general, en el dominio antropológico.

En el humanismo, la reducción trascendental se presentaba como el acto por el que el sujeto (más exactamente, la conciencia) se escinde del mundo y se constituye en absoluto; tras la reducción, todo ser se hace sentido para la conciencia. De ahi su idealísmo implícito, que justifica la acusación de antropomorfismo. Pero este sujeto, fuente de todo el sentido, es desmentido radicalmente por el estructuralismo desde su propio modelo epistemológico: el apriori objetivo, semiótico, es la verdadera fuente del sentido; el sujeto es simplemente el lugar anónimo donde aquél se refleja.

Pero es obvio que el apriori de los signos implica necesariamente también la función semántica del sujeto, que se aplica sobre el universo semiótico. La significación brota, pues, justamente de la conjunción de ambos aprioris, mediados - como antes hemos indicado- por el apriori sociocultural. Pero el estructuralismo (LéviStrauss, Lacan, Foucault) se niega a admitir un sujeto personal, para admitir únicamente ciertas categorías inconscientes del pensa- 
miento. Ello sucede asi porque, propiamente, la metodología estructuralista no supera el plano semiótico (sintáctico). Pero en semántica no basta el principio diferencial, sino que es preciso el principio referencial sobre la base de la diferencia. $Y$ luego el principio subjetivo: un yo concreto realiza la traducción semiótica de la realidad y la asume como propia, completándola al aplicarle su impronta personal.

En definitiva, las posibilidades del análisis estructural le vienen de su modelo semiótico; pero sus limitaciones también. Como tales, los sistemas semióticos no precisan hacer referencia a la historia, a la realidad ni al sujeto; es decir, se sitúan al nivel de sintaxis, según el conocido modelo lingüístico de $\mathrm{Ch}$. Morris. Pero el lenguaje - como cualquier otro sistema o institución sociocultural- queda privado de la dimensión propiamente semántica, que incluye necesariamente una lógica del sentido y de la referencia (Frege), asi como de la dimensión pragmática o nivel de la apropiación del sentido por un sujeto, inmerso en un ámbito sociocultural determinado. Por tanto, la consideración del contexto, de la historia y del sujeto mismo resulta imprescindible en el dominio de las ciencias humanas.

La postergación o el desconocimiento del nivel específicamente humano en el análisis estructural es el responsable directo de los abusos generalizantes y de los equívocos causados por una trasposición metodológica unilateral y precipitada. La equivocidad nace ya en la misma noción de símbolo: en la lingüística estructural el símbolo es un signo sustituíble, puesto que es prácticamente univoco, mientras que en el psicoanálisis o en la antropología cultural el símbolo es siempre polisémico y ambiguo (sueño, parentesco, poesía, mito, ritual), es siempre alegórico y, por tanto, no sustituíble.

Otro defecto muy frecuente en los análisis estructurales aplicados al lenguaje y a otros fenómenos humanos como los mitos, rituales, etc., es su incidencia casi exclusiva en el nivel de información, objetivo, denotativo; el nivel de comunicación, en cambio, más propiamente sociocultural, queda casi sistemáticamente desatendido; e igual acontece con el nivel expresivo, más propiamente subjetivo, connotacional. ¿Puede considerarse correcto el análisis de un mito, en que se atiende preferentemente a su vertiente informativa, mientras se deja en penumbra su valencia comunicativa y expresiva?

José Rubio CaRracedo

Universidad de Valencia

VALENCIA 